\title{
Australian Journal of

\section{Development and productivity of maize in response to spatial arrangement under semiarid condition of Northeastern Brazil}

\author{
Wanderson de Sousa Mendes, Tiago Augusto Drews, João Carlos Medeiros, Jaqueline Dalla Rosa, \\ Adriano Venicius Santana Gualberto, Fábio Mielezrski
}

\author{
Universidade Federal do Piauí, Campus Professora Cinobelina Elvas, 64900-00, Bom Jesus-PI, Brazil
}

\section{*Corresponding author: wmendes_25@hotmail.com}

\begin{abstract}
This study evaluates the development and productivity of maize plants at different spatial arrangements under rainfed conditions in cerrado-caatinga (savannah) transition zone, where characterised as semiarid. The experimental plan was Randomised Blocks Design (RBD) with four replications. This was $3 \times 3$ factorial design with three types of row spacing $(0.35 \mathrm{~m}, 0.50 \mathrm{~m}, 0.75 \mathrm{~m})$ and three types of population density $\left(50,000,65,000\right.$ plants.ha ${ }^{-1}, 80,000$ plants.ha $\left.^{-1}\right)$. The hybrid 30F53YH recommended for the region was used in this experiment. We collected the morphological parameters of five plants in each subplot for six weeks after thinning. Then, productivity data were obtained by weighing harvested grain from two representative lines of each subplot. Furthermore, all data were analysed by performing both statistical tests Tukey $(\mathrm{p} \leq 0.05)$ and Shapiro-Wilk. The best response of maize canopy architecture and productivity was in smaller spacing $(0.35 \mathrm{~m})$ with high population density $\left(80,000\right.$ plants.ha $\left.^{-1}\right)$. However, the total productivity index was high in recommended row spacing and population $(0.70 \mathrm{~m}$ and 50,000 plants.ha-1). Thus, smaller row spacing with a higher population (e.g. 80,000 plants.ha ${ }^{-1}$ ) can deliver better plant distribution density as a solution for production losses due to drought during maize growth stages.
\end{abstract}

Keywords: Growth, row spacing, water stress, yield, Zea mays. Abbreviations: RBD_Randomised Blocks Design; asl_above sea level; TCI_Total Chlorophyll Index.

\section{Introduction}

Spatial, temporal and climate environmental heterogeneity may cause changes in grain production (Williams et al., 2008). High temperatures, low rainfall and other climate events have become more frequent and common (Hatfield, 2011; Tokatlidis, 2013) which may cause major production losses in agriculture. However, the use of cultivars adapted to the region, as well as certain cultural practices (population density, spacing, sowing and tillage) aim to minimize the effects of water stress. The row spacing reduction and the increase of plant density are techniques applied to improve both water and nutrient uptake by plants due to the expansion of leaf area (Testa et al., 2016). Additionally, these factors provide canopy closure in the early vegetative stages (Cox and Cherney, 2001). However, factors such as type of farming, sowing, water availability and soil fertility directly influence optimal plant population (Sangoi et al., 2002). Therefore, it is vital to understand when water is required to fulfil the final grain production (Boyer, 2010). Understanding plant physiology in relation to drought periods is one of the tools that can help crop growth stages, while maintaining or achieving satisfactory levels of productivity.

The method of increasing population density to obtain high productivity has been refuted because each specific region has its own optimal plant population to obtain satisfactory productivity index (Berzsenyi and Tokatlidis, 2012). Thus, optimal plant population reduces abiotic effects (drought), allowing crop development (Mounce et al., 2016), mainly corn. Berzsenyi and Tokatlidis (2012) pointed out that the selection of hybrids that reach maturity in shorter periods, independent of density, can reduce the risk of yield loss in the dry season. The use of high plant densities counterbalances low productivity (Testa et al., 2016). Therefore, in maize culture the row spacing has been reduced and plant densities increased, producing a remarkable final yield (Dourado Neto et al., 2003; Maddonni et al., 2001; Sadeghi et al., 2012).

In this context, biotic and abiotic factors significantly affect maize development. Moreover, the variation in plant density affects maize further than other grass families (Vega et al., 2001; Abuzar et al., 2011) because of the differences in expression of genetic potential ( $\mathrm{Li}$ et al., 2015). The plant density and row spacing change leaf development, plant architecture and maize yield. Therefore, this study aimed to evaluate the development and productivity of maize plants at different spatial arrangements under rainfed conditions in Cerrado-Caatinga (Savannah) transition zone, characterised as semiarid. Furthermore, this research found the optimal row spacing and plant density for maize in semiarid conditions.

\section{Results}

\section{Plant architectural characteristics}

Descriptive statistics of the parameters evaluated in the field into row spacing interaction with population density are below (Fig.3). The highest average plant height was in the row spacing of $0.35 \mathrm{~m}$ with population density of 80,000 plants.ha ${ }^{-1}$, while the lowest average was in the row spacing 
Table 1. Soil chemical analysis of the experimental area.

\begin{tabular}{|c|c|}
\hline Parameters & Measurement units (International System) \\
\hline $\mathrm{pH} \mathrm{CaCl} 2$ & 4.5 \\
\hline & $\%$ \\
\hline Organic Matter & 1.52 \\
\hline Exchangeable Acidity & 2.7 \\
\hline \multirow[t]{2}{*}{ AS } & 46.9 \\
\hline & $\mathrm{mg} \cdot \mathrm{dm}^{-3}$ \\
\hline$P$ & 16.6 \\
\hline $\mathrm{Zn}^{2+}$ & 1.27 \\
\hline $\mathrm{Fe}^{\mathrm{I+}}$ & 346.34 \\
\hline $\mathrm{Mn}^{2+}$ & 48.08 \\
\hline $\mathrm{Cu}^{2+}$ & 0.29 \\
\hline B & 0 \\
\hline \multirow[t]{2}{*}{ S } & 5.9 \\
\hline & $\mathrm{cmol}_{\sigma} \mathrm{dm}^{-3}$ \\
\hline $\mathrm{K}^{+}$ & 0.18 \\
\hline $\mathrm{Ca}^{2+}$ & 1.34 \\
\hline $\mathrm{Mg}^{2+}$ & 0.19 \\
\hline $\mathrm{Al}^{3+}$ & 0.1 \\
\hline $\mathrm{H}+\mathrm{Al}$ & 1.94 \\
\hline Base Saturation & 1.71 \\
\hline Effective CEC & 1.81 \\
\hline Potential CEC & 3.65 \\
\hline
\end{tabular}

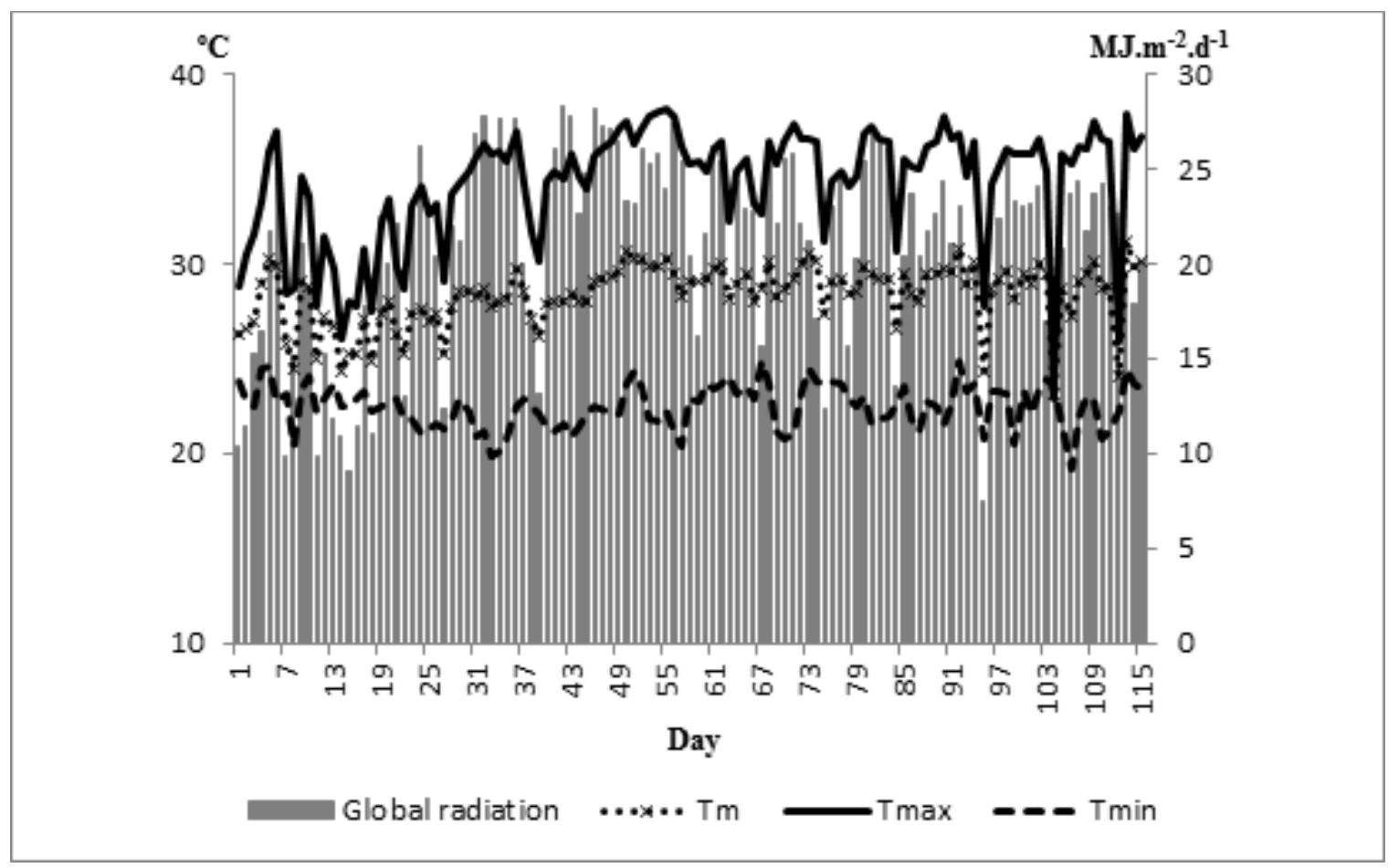

Fig 1. Daily values of average temperatures (Tm), maximum temperature (Tmax), minimum temperature (T min.), and global radiation recorded between $1^{\text {st }}$ January 2016 (Day 1) and $19^{\text {th }}$ March 2016 (Day 73) during the experimental period, Bom Jesus, PI. 
Table 2. Number of maize seeds per square meter meeting the three planting densities with the three row spacing on the experiment in Bom Jesus, PI, Brazil.

\begin{tabular}{cccc}
\hline \multirow{2}{*}{ Row spacing (m) } & \multicolumn{3}{c}{ Plant population/Planting density } \\
\cline { 2 - 4 } & 50000 & 65000 & 80000 \\
\hline 0.35 & 1.75 & 2.28 & 2.80 \\
0.50 & 2.50 & 3.25 & 4.00 \\
0.70 & 3.50 & 4.55 & 5.60 \\
\hline
\end{tabular}

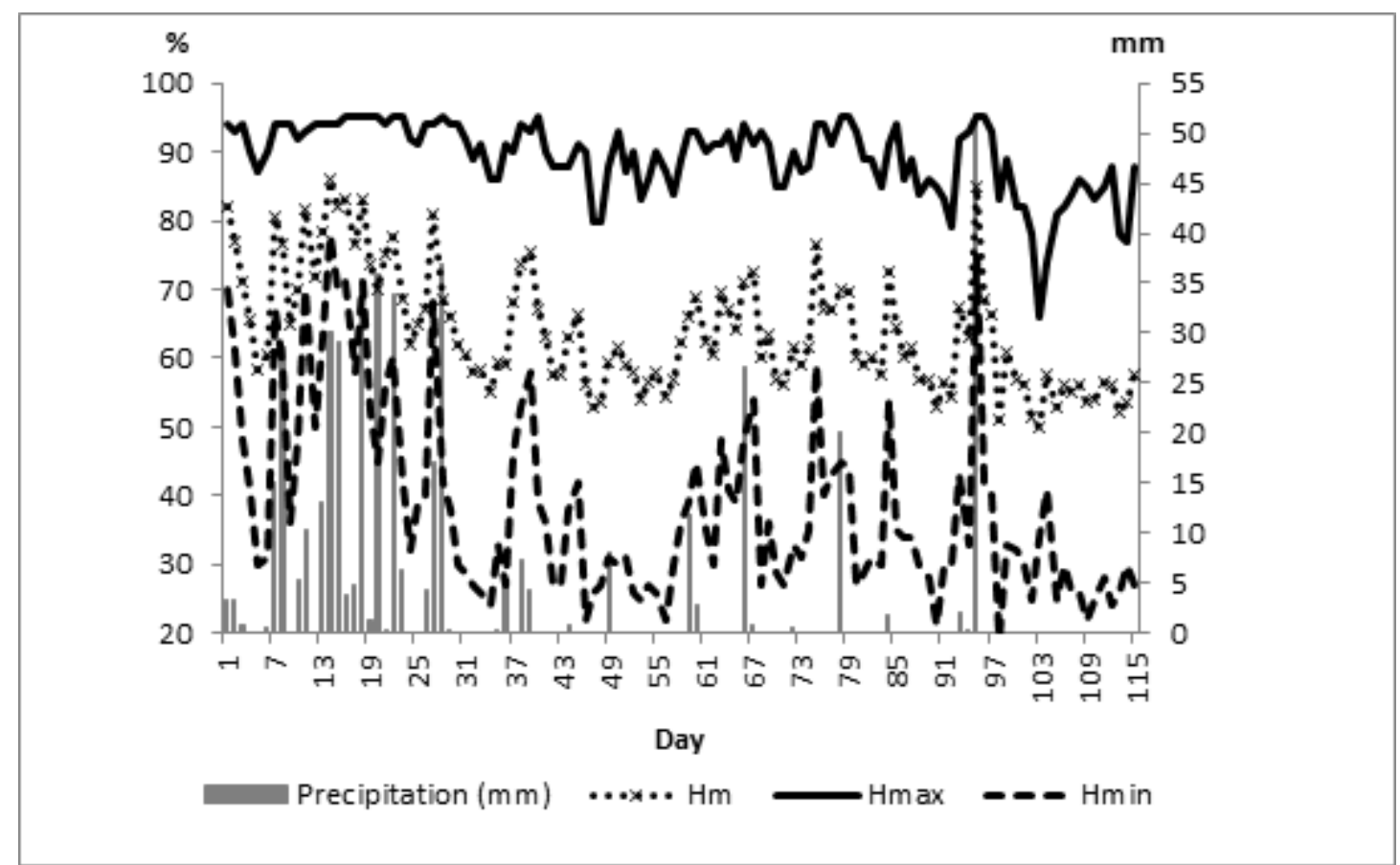

Fig 2. Daily values of average humidity (Hm), maximum humidity (Hmax), minimum humidity (Hmin), and precipitation recorded between $1^{\text {st }}$ January 2016 (Day 1) and $19^{\text {th }}$ March 2016 (Day 73), during the experimental, Bom Jesus, PI.

Table 3. Analysis of variance (ANOVA) of plant height, stem diameter, number of leaves, number of nodes and total chlorophyll index, depending on the interaction between row spacing (RS) and plant population (P).

\begin{tabular}{ccccccc}
\hline & & \multicolumn{5}{c}{ MS } \\
\cline { 3 - 7 } Source of \\
\cline { 3 - 7 } Variation & DF & $\begin{array}{c}\text { Plant } \\
\text { height } \\
(\mathrm{cm})\end{array}$ & $\begin{array}{c}\text { Stem } \\
\text { diameter } \\
(\mathrm{mm})\end{array}$ & $\mathrm{N}^{\circ}$. Leaves & $\mathrm{N}^{\circ}$. Nodes & $\begin{array}{c}\text { Total } \\
\text { Chlorophyll } \\
\text { Index (TCI) }\end{array}$ \\
\hline Block & 3 & $0.42148^{\mathrm{S}}$ & $0.203990^{\mathrm{S}}$ & $0.098563^{\mathrm{S}}$ & $0.146294^{\mathrm{S}}$ & $0.148500^{\mathrm{S}}$ \\
RS & 2 & $0.04746^{\mathrm{NS}}$ & $0.142912^{\mathrm{S}}$ & $0.001173^{\mathrm{NS}}$ & $0.000966^{\mathrm{NS}}$ & $0.215221^{\mathrm{S}}$ \\
P & 2 & $0.00440^{\mathrm{NS}}$ & $0.203050^{\mathrm{S}}$ & $0.032499^{\mathrm{NS}}$ & $0.013327^{\mathrm{NS}}$ & $0.032212^{\mathrm{NS}}$ \\
RS X P & 4 & $0.24174^{\mathrm{S}}$ & $0.124859^{\mathrm{S}}$ & $0.057365^{\mathrm{S}}$ & $0.060730^{\mathrm{S}}$ & $0.149185^{\mathrm{S}}$ \\
Residuals & 1068 & 0.049380 & 0.024674 & 0.012250 & 0.016349 & 0.017823 \\
Total & 1079 & & & & & 8.18 \\
CV (\%) & & 17.14 & 13.27 & 14.52 & 17.69 & \\
\hline
\end{tabular}



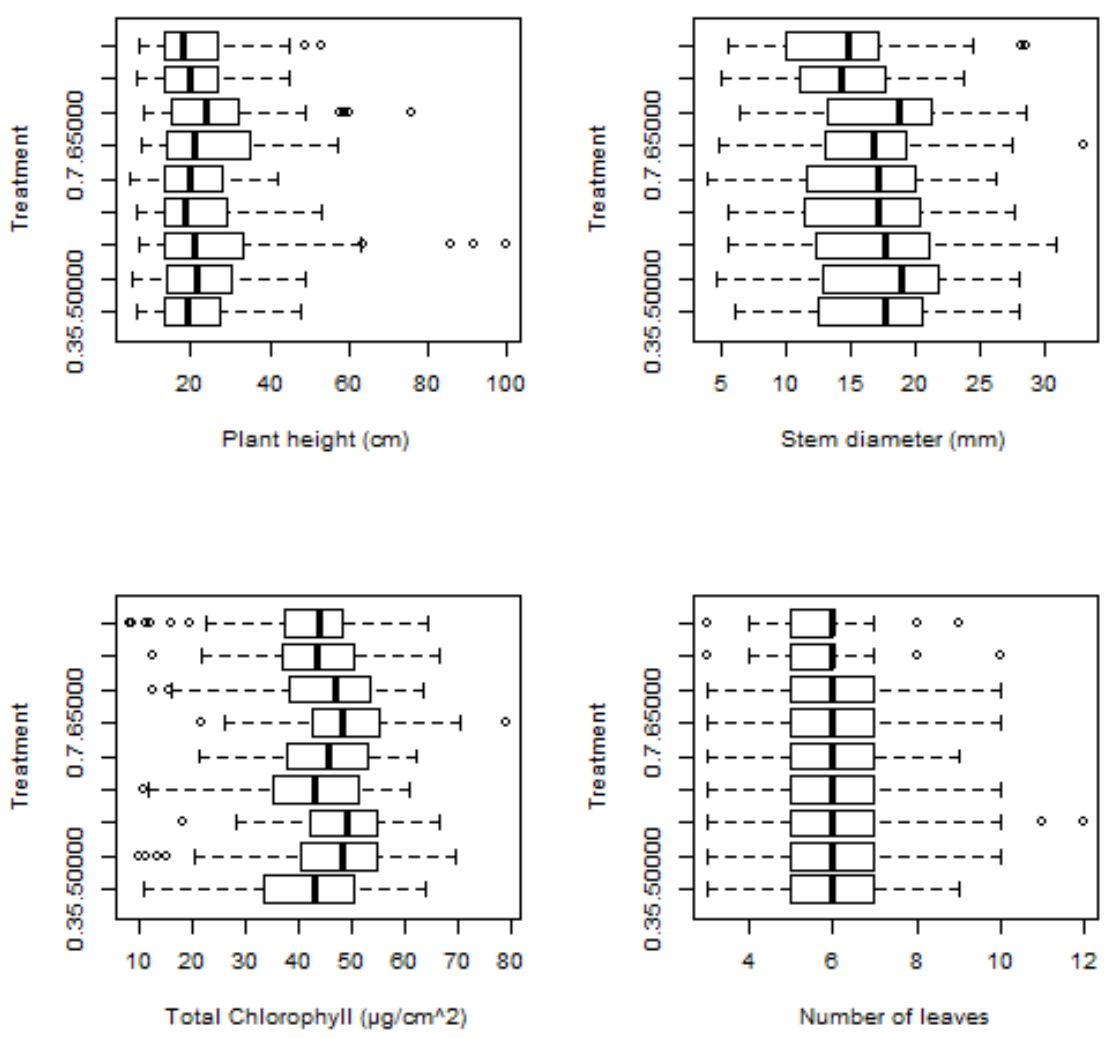

Fig 3. Minimum values, $1^{\text {st }}$ quartile, median, average, $3^{\text {rd }}$ quartiles and maximum plant height, total chlorophyll, leaf number and stem diameter resulting between the interaction between plant row spacing and plant population.

Table 4. Average values of plant height, stem diameter, number of leaves, number of nodes and total chlorophyll index, depending on the interaction between row spacing and planting density.

\begin{tabular}{|c|c|c|c|c|c|c|}
\hline $\begin{array}{c}\text { Row } \\
\text { spacing }\end{array}$ & Plants.ha ${ }^{-1}$ & $\begin{array}{c}\text { Plant } \\
\text { Height } \\
\text { (cm) }\end{array}$ & $\begin{array}{c}\text { Stem } \\
\text { diameter } \\
(\mathbf{m m})\end{array}$ & $\begin{array}{c}\mathrm{N}^{\circ} \text {. } \\
\text { Leaves }\end{array}$ & $\begin{array}{c}\mathrm{N}^{\circ} \text {. } \\
\text { Nodes }\end{array}$ & $\begin{array}{c}\text { Total } \\
\text { Chlorophyll } \\
\text { Index (TCI) }\end{array}$ \\
\hline \multirow{3}{*}{$0.35 \mathrm{~m}$} & 50000 & $21.04 b^{*}$ & 17.05 & $5 \mathrm{~b}$ & $5 \mathrm{~b}$ & $40.81 \mathrm{~b}$ \\
\hline & 65000 & $20.75 \mathrm{~b}$ & 16.22 & 6 & 5 & $45.08 \mathrm{~b}$ \\
\hline & 80000 & $25.40 \mathrm{a}$ & $17.69 \mathrm{a}$ & $6 a$ & $6 \mathrm{a}$ & 45.14 \\
\hline \multirow{3}{*}{$0.50 \mathrm{~m}$} & 50000 & $22.85 \mathrm{ab}$ & 17.60 & $6 a$ & $6 a$ & $46.96 \mathrm{a}$ \\
\hline & 65000 & $21.43 \mathrm{ab}$ & 16.15 & 6 & 5 & $45.08 \mathrm{~b}$ \\
\hline & 80000 & $20.96 \mathrm{~b}$ & $14.31 \mathrm{~b}$ & $5 \mathrm{~b}$ & $5 a b$ & 43.13 \\
\hline \multirow{3}{*}{$0.70 \mathrm{~m}$} & 50000 & $25.63 \mathrm{a}$ & 16.88 & $6 a$ & $6 a$ & $48.15 \mathrm{a}$ \\
\hline & 65000 & $24.64 \mathrm{a}$ & 16.10 & 6 & 5 & $48.49 \mathrm{a}$ \\
\hline & 80000 & $20.20 \mathrm{~b}$ & $14.14 \mathrm{~b}$ & $5 \mathrm{~b}$ & $5 b$ & 42.22 \\
\hline \multicolumn{2}{|c|}{$\begin{array}{l}\text { Coefficient of } \\
\text { Variation (\%) }\end{array}$} & 17.14 & 13.27 & 14.52 & 17.69 & 8.18 \\
\hline
\end{tabular}




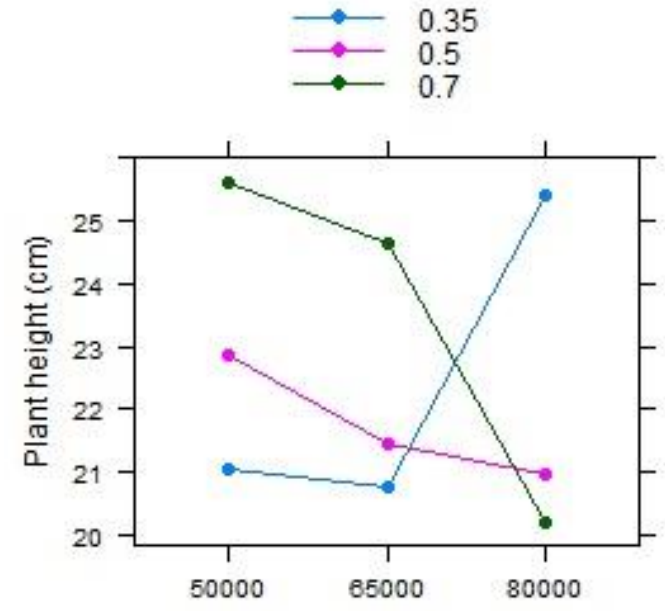

Population density (plants/ha)

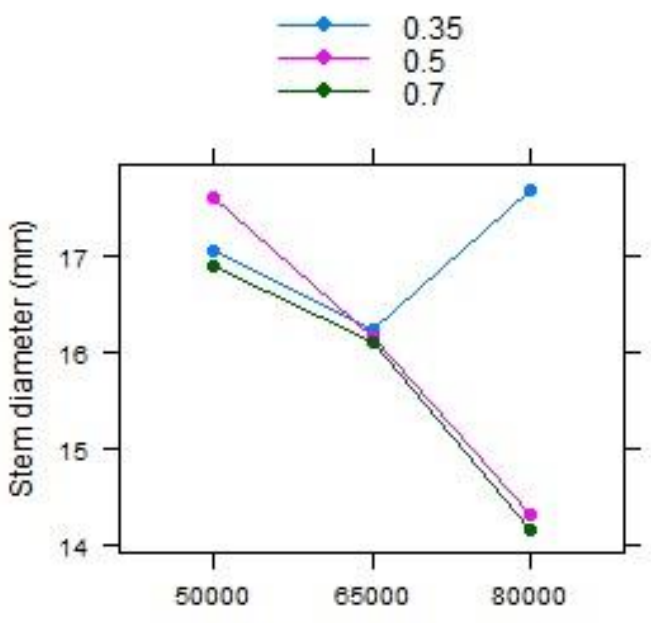

Population density (plants/ha)

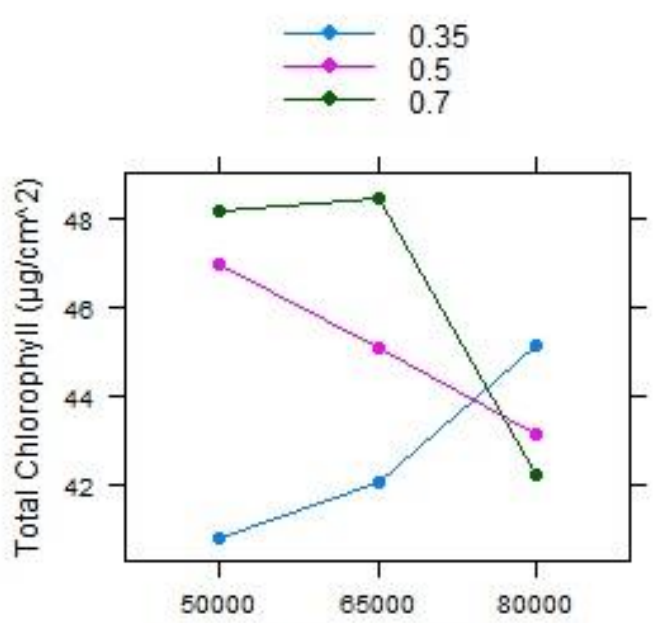

Population density (plants/ha)

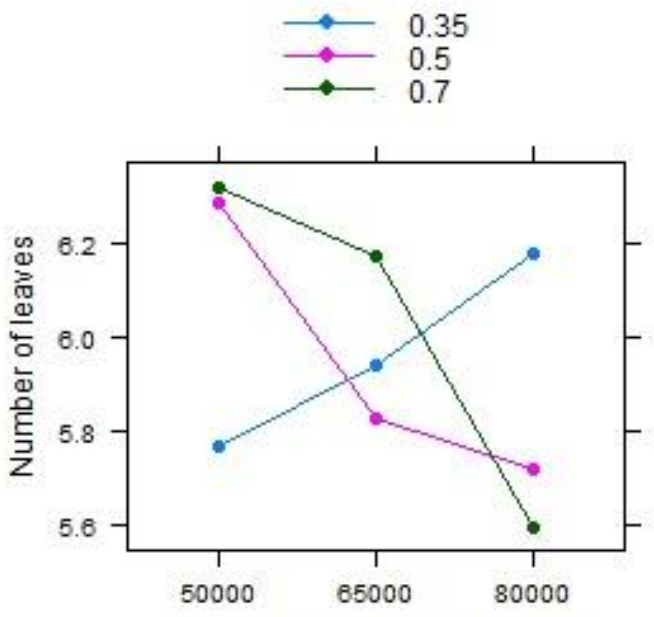

Population density (plants/ha)

Fig 4. Levels of interaction on the parameters: plant height, total chlorophyll, stem diameter and number of leaves in different row spacing and plant population.

Table 5. Analysis of Variance of maize yield gain in the interaction between row spacing (RS) and plant population (P). ${ }^{\text {ns }}$ No significant, ${ }^{\mathrm{S}}$ Significant to $5 \%$ by Tukey test and $\mathrm{F}$ test, $\mathrm{DF}=$ degrees of freedom, MS = mean square, CV = coefficient of variation, $\mathrm{P}=$ plant population, $\mathrm{RS}=$ row spacing.

\begin{tabular}{ccc}
\hline & & MS \\
\cline { 3 - 3 } Sources of Variation & DF & Yield gain (kg/ha) \\
\hline Block & 3 & $7.1210^{\mathrm{NS}}$ \\
RS & 2 & $1.6070^{\mathrm{NS}}$ \\
P & 2 & $1.0343^{\mathrm{NS}}$ \\
RS X P & 4 & $3.7778^{\mathrm{NS}}$ \\
Residuals & 24 & 2.0369 \\
Total & 35 & \\
CV (\%) & & 31.82 \\
\hline
\end{tabular}




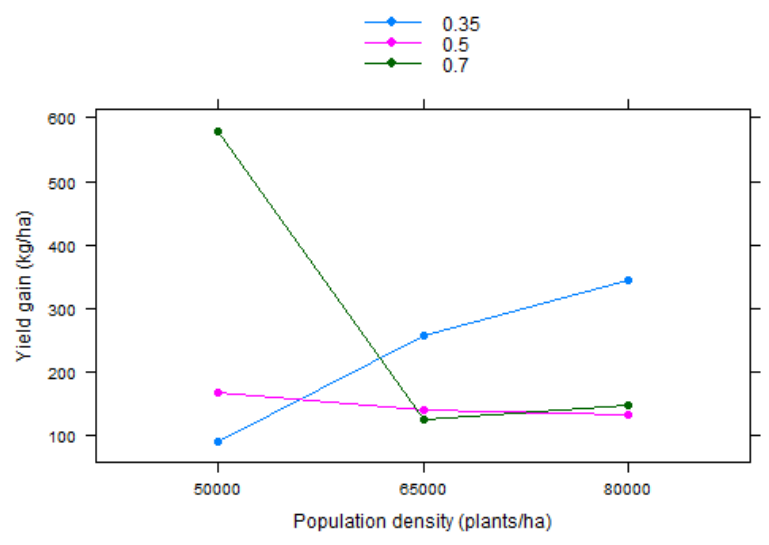

Fig 5. Levels of interaction on the parameter yield gain in different row spacing and planting densities.
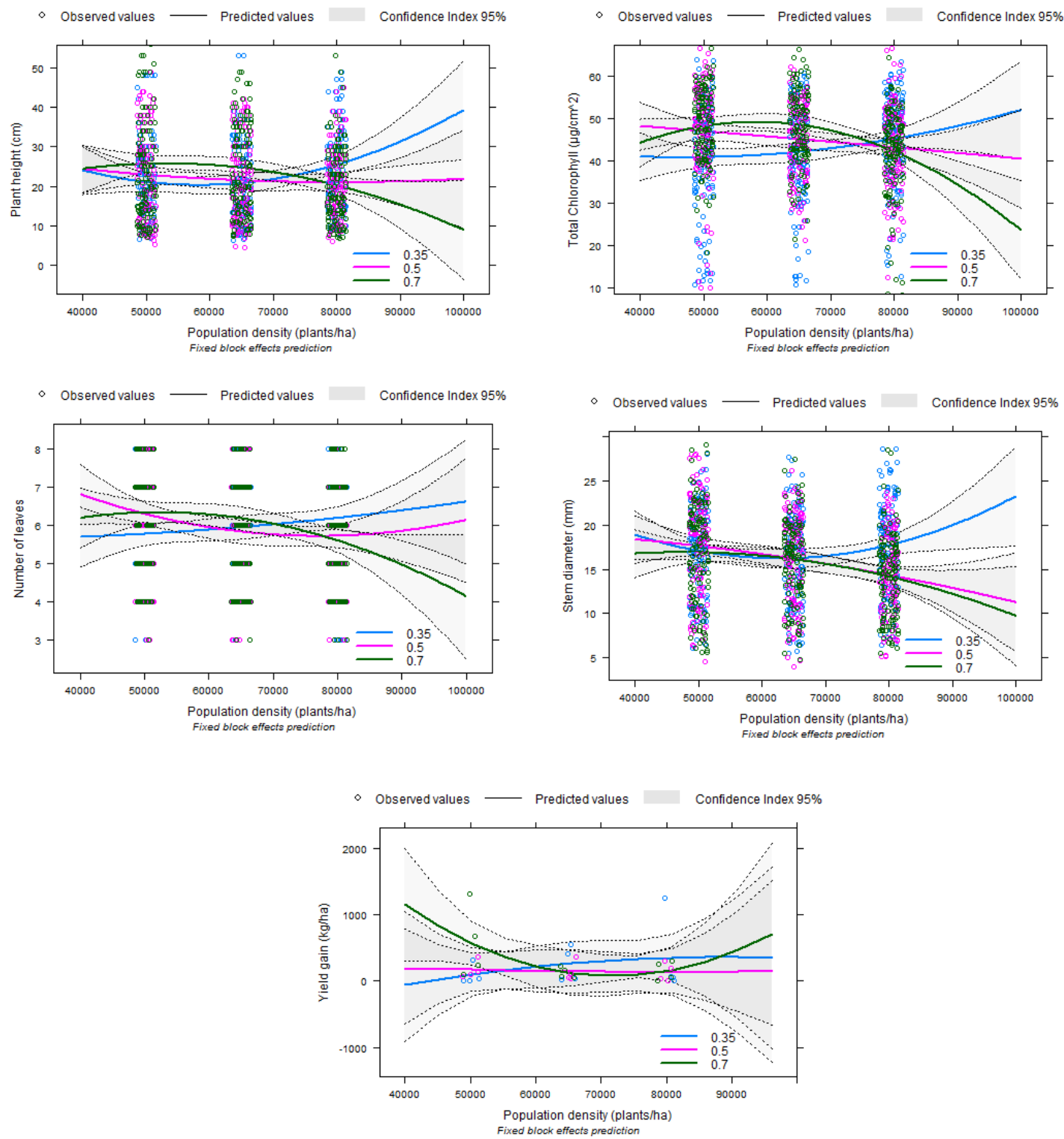

Fig 6. Matrix model prediction of plant height, Total Chlorophyll Index (TCI), stem diameter and number of leaves in the three corn row spacing $(0.35 \mathrm{~m}, 0.50 \mathrm{~m}, 0.70 \mathrm{~m})$ and planting densities ranging from 40000 plants.ha $^{-1}$ to 100000 plants.ha $^{-1}$. 
of $0.70 \mathrm{~m}$ with population of 80,000 plants.ha ${ }^{-1}$. Analysing the stem diameter, the best means were observed in treatments $0.50 \mathrm{~m}-50,000$ plants.ha $^{-1}$, and $0.35 \mathrm{~m}-80,000$ plants.ha ${ }^{-1}$. Moreover, the treatments $0.50 \mathrm{~m}-80,000$ plants.ha ${ }^{-1}$ and $0.70 \mathrm{~m}-80,000$ plants.ha $^{-1}$ showed the lowest averages in comparison with other treatments. The average of the Total Chlorophyll Index (TCI) was better in the following treatments $0.50 \mathrm{~m}$ - 50,000 plants.ha ${ }^{-1}, 0.70 \mathrm{~m}-50,000$ plants.ha $^{-1}, 0.70 \mathrm{~m}-65,000$ plants.ha $^{-1}$. Additionally, TCI was inferior to others in the treatments $0.35 \mathrm{~m}-50,000$ plants.ha $^{-1}, 0.35 \mathrm{~m}-65,000$ plants.ha $^{-1}, 0.50 \mathrm{~m}-80,000$ plants.ha ${ }^{-1}$, and $0.70 \mathrm{~m}-80,000$ plants.ha ${ }^{-1}$. The difference in the number of leaves in the Fig 3 was not clear. However, we can observe that there are significant difference between the number of leaves, stem diameter, plant height and TCI within each level of treatment as well as there is an interaction between these factors.

\section{Plant morphological response}

The analysis of variance showed that the maize morphological response was statistically significant within row spacing and population density at $5 \%$ for the F-test (Table 3). In addition, the block effect was significant resulting in its elimination on the predict model output presented in subsection 3.3. The plant height, number of leaves and node number had no significant effect in three row widths. However, all parameters showed a significant response in populations of 50,000, 65,000 and 80,000 plants.ha ${ }^{-1}$.

The coefficient of variation (CV) was considered medium for all morphological parameters of plants we analysed, except for TCI. This means a good precision. Nevertheless, the TCI had a low CV, i.e., high precision.

The Tukey's test at 5\% (Table 4) showed that the mean height of plants in the $0.35 \mathrm{~m}$ row spacing with 50,000 plants.ha ${ }^{-1}$ do not differ between them. However, the interaction of $0.35 \mathrm{~m}$ and 50,000 plants. $\mathrm{ha}^{-1}$ displayed statistical differences between their means. Moreover, there is a significant difference between these two rows spacing in the population density of 80,000 plants.ha ${ }^{-1}$. Regarding to stem diameter, only the population density of 80,000 plants.ha $^{-1}$ had significant difference in their means. Additionally, there was statistical difference into both parameters number of leaves and node number in the population density of 50,000 and 80,000 plants.ha ${ }^{-1}$. Finally, evaluating the TCI, there was difference between means only into the population density of 80,000 plants.ha ${ }^{-1}$.

\section{Productivity and matrix prediction model}

The total and average productivity (Fig.5) within each treatment were considered higher in the $0.70 \mathrm{~m}$ row spacing with population size of 50,000 plants per hectare $(578.98$ $\mathrm{kg} \cdot \mathrm{ha}^{-1}$ ) and the $0.35 \mathrm{~m}$ row spacing with population size of 80,000 plants per hectare $\left(344.79 \mathrm{~kg} \cdot \mathrm{ha}^{-1}\right)$. The worst average productivity was at 0.35 row width with population density of 50,000 plants per hectare $\left(91.26 \mathrm{~kg} \cdot \mathrm{ha}^{-1}\right)$. So that, the Tukey's test at $5 \%$ displayed no significant difference between those treatments means (Table 5). However, the Shapiro-Wilk's test at $5 \%$ considered normal.

The prediction of corn morphological development and productivity were based on matrix model, eliminating the block effect into treatments. This model may identify plant responses to different population density by measuring data in the field experiment. Its confidence index is $95 \%$. In this study, population density ranged from 50,000 plants.ha $^{-1}$ to 80,000 plants.ha $^{-1}$ (Fig 6).

\section{Discussion}

Canopy closure and better canopy architecture are result from reduction in row spacing as well as increasing population density. This allows $\mathrm{C}_{4}$ plants to improve its light absorption efficiency and its photo-assimilate production (Hatzig et al., 2010). Maize physiological response to both row spacing and high planting density was positive in relation to other treatments resembling the results of some authors (Maddonni et al., 2001; Blumenthal et al., 2003; Berzsenyi and Tokatlidis, 2012). During the vegetative growth in maize, the favourable environmental conditions allowed us to obtain tall plants with large stalk diameter in reduced row spacing and higher planting density.

During the transitional period of growth (vegetative stage to reproductive stage), maize crop suffered water stress (Fig 2). However, maize crop showed good productivity index in reduced spacing and high planting density, compared to the other treatments (Berzsenyi and Tokatlidis, 2012), except for planting density and row spacing recommended by maize hybrid companies. These results reflect total compensation of productivity at expense of loss per plant (Testa et al., 2016) due to changes in plant morphology grown in high planting densities. Furthermore, reduced row spacing helped out abrupt canopy closure (Dourado Neto et al., 2003, Hörbe et al., 2013).

The radiation absorption efficiency and biomass production of maize plants may have helped its development even they were under water deficit situation (Hao et al., 2016). In order to predict maize planting density within the row spacing analysed, the matrix prediction model can be a good reference for the future researches. All models showed positive results for reduced row spacing and planting density above the recommend. Nevertheless, the abiotic factors have to be favourable to maize growth. Moreover, productivity losses are significant due to climate change in the rainy season. Although, maize is a $\mathrm{C}_{4}$ plant, it is relatively adapted to the short periods of drought. But we see in this experiment that the lack of water in maize reproductive stage leads to reduced plants yield (Lopes et al., 2011; Berzsenyi and Tokatlidis, 2012). However, it is essential to follow commercial recommendation for maize planting density and row spacing, although we report promising results about increasing planting density and reduced row spacing in this study. This will print on field better plant adaptation and genotype-environment interaction. The optimum planting density will display positive responses, if farmers use the recommended maize hybrid for their specific geographic region due to its adaptability (Tokatlidis et al., 2011; Tokatlidis, 2013; Sadeghi et al., 2012; Maddonni et al., 2001).

\section{Materials and Methods}

\section{Study area}

The experiment was conducted at the Federal University of Piauí, Campus Professor Cinobelina Elvas (09 04' 47' S latitude, 44 19' 37.60" W longitude; $285 \mathrm{~m}$ asl), Bom Jesus, PI, Brazil. Figs 1 and 2 show the weather data for the 115day-period starting from $1^{\text {st }}$ January, 2016 to $19^{\text {th }}$ March, 2016. The soil is characterised as Oxisols, medium texture and its chemical characteristics are shown in Table 1. 
Interpreting soil test results, we applied $120 \mathrm{~kg} \mathrm{~N}$. ha ${ }^{-1}$ covering V1, V5 and V8 growth stages, that is, $40 \mathrm{~kg} \mathrm{~N} \cdot \mathrm{ha}^{-1}$ per growth stage. Moreover, doses of $60 \mathrm{~kg} \mathrm{~K}_{2} \mathrm{O}$. ha ${ }^{-1}$ and 80 $\mathrm{kg} \mathrm{P}_{2} \mathrm{O}_{5}$ were incorporated into the soil one week before sowing. Urea, potassium chloride and single Superphosphate were the commercial mineral fertilizers used as nitrogen, potassium and phosphorus sources. Sowing was performed under poaceae straw remained in the study area on $8^{\text {th }}$ January 2016 (the beginning of the rainy season). Additionally, systemic and contact insecticides were applied to control Spodoptera fungiperda during the experiment.

\section{Plant material and experimental design}

In this study, we used the corn hybrid $30 \mathrm{~F} 53 \mathrm{YH}$ that is adapted to Cerrado biome. The experimental design was randomized blocks distributed randomly with four replications, in a factorial $3 \times 3$, implying three types of row spacing $(0.35 \mathrm{~m}, 0.50 \mathrm{~m}, 0.75 \mathrm{~m})$ and three population densities $\left(50,000\right.$ plants.ha ${ }^{-1}, 65,000$ plants.ha $^{-1}, 80,000$ plants.ha ${ }^{-1}$ ). The maize hybrid used and recommended for the region was $30 \mathrm{~F} 53 \mathrm{YH}$. Sowing was done manually in a row according to the seed density shown in Table 2.

The thinning occurred at V2 growth stage to maintain a desired population in each subplot. This consists of 4 rows with $3 \mathrm{~m}$ length. Therefore, that is, the sidelines and $0.5 \mathrm{~m}$ from the end of the central lines comprehended all borders. Finally, we used mechanical weed control during the experiment.

\section{Data collection}

The collection started after thinning. We randomly selected five plants in the two centre lines in each subplot. This led us to have 180 plants. The plant height, stem diameter, chlorophyll content, number of leaves and number of nodes were recorded during six weeks (1080 observations). The materials used for measurement of parameters were: ruler, measuring tape, electronic sliding calliper and chlorophyll trademark ClorofiLOG® model CFL 1030. The height of the corn plant was defined by measuring from the ground surface to the line perpendicular to the last leaf set. Chlorophyll readings were taken from the upper third of the last two fully open leaves on each plant evaluated. The count of nodes and leaf number were performed visually. Productivity was measured from the collection of all maize ears of the two central rows of each subplot and the grains were weighed on an analytical balance. Then, the average yield was calculated for one hectare.

\section{Statistical analysis}

We used the $\mathrm{R}$ program ( $\mathrm{R}$ Core Team, 2016) to process and analyse data from plant height, stem diameter, chlorophyll, leaf number, productivity, interaction between plant population and spacing. Furthermore, all data were analysed by performing both statistical tests Tukey $(\mathrm{p}<0.05)$ and Shapiro-Wilk, analysis of variance (ANOVA), unfolding the interactions (population density and spacing) and free prediction of the effect of blocks through both $\mathrm{R}$ packages ExpDes and Agricolae. Additionally, all data were transformed by $\log (\mathrm{x})$ to obtain homogenous variances.

\section{Conclusion}

Maize crop showed optimal parametric response (Morphological and physiological) with reduced row spacing
$(0.35 \mathrm{~m})$ and high planting density (80,000 plants.ha $\left.{ }^{-1}\right)$. Additionally, reduced row spacing with high planting density can be a solution for maize yield loss due to dry season based on this study. Nevertheless, it is necessary to evaluate other plant materials.

\section{Acknowledgement}

The authors thank to the Federal University of Piauí for field support in the experiment.

\section{References}

Abuzar MR, Sadozai GU, Baloch MS, Baloch AA, Shah IH, Javaid T, Hussain N (2011) Effect of plant population densities on yield of maize. J Anim Plant Sci. 21(4):692695.

Berzsenyi Z, Tokatlidis IS (2012) Density dependence rather than maturity determines hybrid selection in dryland maize production. Agron J. 104(2): 331-336.

Blumenthal JM, Lyon DJ, Stroup WW (2003) Optimal plant population and nitrogen fertility for dryland corn in western Nebraska. Agron J. 95(4): 878-883.

Boyer JS (2010) Drought decision-making. J Exp Bot. 61(13): 3493-3497.

Cox WJ, Cherney DJ (2001) Row spacing, plant density, and nitrogen effects on corn silage. Agron J. 93(3): 597-602.

Dourado Neto D, Palhares M, Vieira PA, Manfron PA, Medeiros SLP, Romano MR (2003) Efeito da população de plantas e do espaçamento sobre a produtividade de milho. Rev Bras Milho Sorgo. 2(3): 63-77.

Hao B, Xue Q, Marek TH, Jessup KE, Hou X, Xu W, Bynum ED, Bean BW (2016) Radiation-use efficiency, biomass production, and grain yield in two maize hybrids differing in drought tolerance. J Agron Crop Sci. 202(4): 269-280.

Hatfield JL, Boote KJ, Kimball BA, Ziska LH, Izaurral de RC, Ort D, Thomson AM, Wolfe D (2011) Climate impacts on agriculture: implications for crop production. Agron J. 103(2): 351-370.

Hatzig S, Kumar A, Neubert A, Schubert S (2010) PEPCarboxylase activity: a comparison of its role in a $\mathrm{C} 4$ and a C3 species under salt stress. J Agron Crop Sci. 196(3): 185192.

Hörbe TAN, Amado TJC, Ferreira ADO, Alba PJ (2013) Optimization of corn plant population according to management zones in southern Brazil. Precis Agric. 14(4): 450-465.

Li J, Xie RZ, Wang KR, Ming B, Guo YQ, Zhang GQ, Li SK (2015) Variations in maize dry matter, harvest index, and grain yield with plant density. Agron J. 107(3): 829-834.

Lopes MS, Araus JL, Van Heerden PD, Foyer CH (2011) Enhancing drought tolerance in C4 crops. J Exp Bot. 62(9): 3135-3153.

Maddonni GA, Otegui ME, Cirilo AG (2001) Plant population density, row spacing and hybrid effects on maize canopy architecture and light attenuation. Field Crop Res. 71(3): 183-193.

Mounce RB, O'Shaughnessy SA, Blaser BC, Colaizzi PD, Evett SR (2016) Crop response of drought-tolerant and conventional maize hybrids in a semiarid environment. Irrigation Sci. 34(3): 231-244.

$\mathrm{R}$ Core Team (2016) R: A language and environment for statistical computing. Available at: <https://www.rproject.org/>. Accessed on July 15, 2016.

Sadeghi M, Naderi A, Lak S, Fathi GA (2012) Evaluation of plant population density on growth, grain yield and yield 
components of four maize hybrids. Adv Environ Biol. 6(1): 327-333.

Sangoi L, Gracietti MA, Rampazzo C, Bianchetti P (2002) Response of brazilian maize hybrids from different eras to changes in plant density. Field Crop Res. 79(1): 39-51.

Testa G, Reyneri A, Blandino M (2016) Maize grain yield enhancement through high plant density cultivation with different inter-row and intra-row spacings. Eur $\mathbf{J}$ Agron. 72(1): 28-37.

Tokatlidis IS, Has V, Melidis V, Has I, Mylonas I, Evgenidis G, Compandean A, Ninou E, Fasoula V (2011) Maize hybrids less dependent on high plant densities improve resource use efficiency in rainfed and irrigated conditions. Field Crop Res. 120 (3): 345-351.
Tokatlidis IS (2013) Adapting maize crop to climate change. Agron Sustain Dev. 33(1): 63-79.

Vega CRC, Andrade FH, Sadras VO (2001) Reproductive partitioning and seed set efficiency in soybean, sunflower and maize. Field Crop Res. 72(3): 163-175.

Williams CL, Liebman M, Edwards JW, James DE, Singer JW, Arritt R, Herzmannm D (2008) Patterns of regional yield stability in association with regional environmental dharacteristics. Crop Sci. 48(4):1545-1559. 